\title{
ANTI-CORROSION PERFORMANCE OF 1,3-BENZOTHIAZOLE ON 410 MARTENSITIC STAINLESS STEEL IN $\mathrm{H}_{2} \mathrm{SO}_{4}$
}

\author{
ROLAND TOLULOPE LOTO \\ Department of Mechanical Engineering, \\ Covenant University, Ota, Ogun State, Nigeria \\ tolu.loto@gmail.com
}

Received 14 March 2017

Revised 30 May 2017

Accepted 16 June 2017

Published 21 July 2017

\begin{abstract}
The corrosion inhibition effect of synthesized 1,3-benzothiazole at very low concentrations on 410 martensitic stainless steel in $3 \mathrm{MH}_{2} \mathrm{SO}_{4}$ solution was studied through potentiodynamic polarization and weight loss measurements. The observation showed that the organic compound performed effectively with average inhibition efficiencies of $94 \%$ and $98 \%$ at the concentrations studied from both electrochemical methods due to the inhibition action of protonated inhibitor molecules in the acid solution. The amine and aromatics functional groups of the molecules active in the corrosion inhibition reaction were exposed from Attenuated total reflectance-Fourier transform infrared spectroscopy (ATR-FTIR) spectroscopic analysis. Thermodynamic calculations showed cationic adsorption to be chemisorption adsorption, obeying the Langmuir adsorption isotherm. Images from optical microscopy showed an improved morphology in comparison to images from corroded stainless steel. Severe surface deterioration and macro-pits were observed in the uninhibited samples.
\end{abstract}

Keywords: Steel; corrosion; inhibitor; acid; adsorption.

\section{Introduction}

$\mathrm{H}_{2} \mathrm{SO}_{4}$ is an important industrial chemical extensively applied over a wide range of applications involving the use of stainless steels, such as in fertilizer production, paper bleaching for chlorine dioxide generation, water treatment facilities, steel manufacturing, petroleum refinery and so on. ${ }^{1}$ Due to the presence of sulfate anions $\left(\mathrm{SO}_{4}^{2-}\right)$ and other impurities in these environments, stainless steels suffer from severe surface deterioration, pitting and general corrosion and in some cases cracks due to hydrogen embrittlement leading to catastrophic failure and huge cost overheads. ${ }^{2,3}$ There are numerous corrosion control measures for stainless steels in acidic media encountered in industry. ${ }^{4}$ Chemical compounds known as inhibitors, especially those of organic origin, are most often used, being the most practical and cost-effective method for corrosion control. Selection and application of appropriate inhibitors are very important due to the complex nature of corrosive environments. ${ }^{5,6}$ These organic-inhibiting compounds contain heteroatoms such as sulfur, nitrogen and

This is an Open Access article published by World Scientific Publishing Company. It is distributed under the terms of the Creative Commons Attribution 4.0 (CC-BY) License. Further distribution of this work is permitted, provided the original work is properly cited. 
oxygen, aromatic rings and/or multiple bonds that facilitate adsorption of inhibitor molecules onto the steel, thereby stifling the corrosion reaction processes through adsorption. ${ }^{7-10}$ Benzothiazole is an organic compound used as accelerators for the vulcanization of rubbers, as an insecticide, in the production of dyes and pharmaceutical drugs and as a food-flavoring agent. ${ }^{11}$ The corrosion inhibition properties of benzothiazole derivatives have been proven to be effective in previous studies on carbon steel in $\mathrm{HCl}$ solution, copper in neutral chloride solutions and austenitic stainless steel (type 304). ${ }^{12-14} 410$ martensitic stainless steel is applied in petroleum fractionating structures, mine ladder rungs, gas turbines, shafts, pumps, valves and as bolts, screws, bushings and nuts. ${ }^{15}$ This research aims to study the corrosion inhibition effect of 1,3benzothiazole on 410 martensitic stainless steel (41000SS) in $3 \mathrm{MH}_{2} \mathrm{SO}_{4}$ solution through the use of potentiodynamic polarization and weight loss technique. The inhibitor functional groups responsible for adsorption will be determined through ATR-FTIR spectroscopy, and surface morphology of inhibited and corroded steel specimens will be analyzed through optical microscopy. Corrosion kinetic and thermodynamic properties will be evaluated.

\section{Experimental Methods}

\subsection{Materials and preparation}

410 martensitic stainless steel (S41000SS) sourced commercially had a nominal composition (wt.\%) of $17.3 \% \mathrm{Cr}, 1.5 \% \mathrm{Ni}, 1.7 \% \mathrm{Si}$ and balance Fe. The cylindrical steel specimens (length, $1 \mathrm{~cm}$ and diameter, $0.8 \mathrm{~cm}$ ) after machining were abraded with silicon carbide papers $(80,320,600,800$ and 1000) before washing with distilled water and propanone and kept in a desiccator for coupon analysis and potentiodynamic polarization test according to ASTM G1-03 (2011). ${ }^{16}$ 1,3-Benzothiazole (BEZT), obtained from BOC Sciences, USA, belongs to the group of xenobiotic compounds that contain a thiazole ring fused with benzene ring and has a wide range of biological properties and applications. They have a molecular formula of $\mathrm{C}_{7} \mathrm{H}_{5} \mathrm{NS}$ and a molar mass of $135.1863 \mathrm{~g} / \mathrm{mol}$. The molecular structure is shown in Fig. 1. BEZT was prepared in concentrations of $9.246 \times 10^{-6}$, $1.849 \times 10^{-5}, 2.774 \times 10^{-5}, 3.698 \times 10^{-5}, 4.623 \times$ $10^{-5}$ and $5.547 \times 10^{-5} \mathrm{M}$ in $200 \mathrm{~mL}$ of $3 \mathrm{M} \mathrm{H}_{2} \mathrm{SO}_{4}$

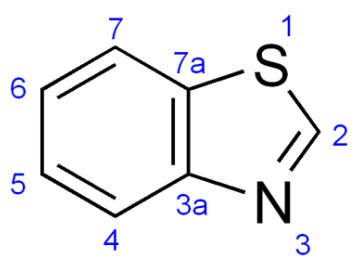

Fig. 1. (Color online) Molecular structure of BEZT.

solution, prepared from grade of $\mathrm{H}_{2} \mathrm{SO}_{4}$ acid (98\%) with deionized water.

\subsection{Potentiodynamic polarization technique}

Polarization measurements were carried out at $30^{\circ} \mathrm{C}$ using a three-electrode system and glass cell containing $200 \mathrm{~mL}$ of the corrosive test solution at predetermined concentrations of BEZT with Digi-Ivy 2311 electrochemical workstation. Cylindrical S41000SS electrodes mounted in acrylic resin with an exposed surface area of $0.50 \mathrm{~cm}^{2}$ were prepared according to ASTM G59-97(2014). ${ }^{17}$ Polarization plots were obtained at a scan rate of $0.0015 \mathrm{~V}$ versus $\mathrm{Ag} / \mathrm{AgCl} / \mathrm{s}$ between potentials of $-1.5 \mathrm{~V}$ versus $\mathrm{Ag} /$ $\mathrm{AgCl}$ and $+1.5 \mathrm{~V}$ versus $\mathrm{Ag} / \mathrm{AgCl}$, according to ASTM G102-89(2015). ${ }^{18}$ Platinum rod was used as the counter electrode and silver chloride electrode $(\mathrm{Ag} / \mathrm{AgCl})$ as the reference electrode. Corrosion current density $\left(J_{\mathrm{cr}}, \mathrm{A} / \mathrm{cm}^{2}\right)$ and corrosion potential $\left(E_{\mathrm{cr}}, \mathrm{V}\right.$ versus $\mathrm{Ag} / \mathrm{AgCl}$ ) values were obtained using the Tafel extrapolation method, whereby the estimated corrosion current, $I_{\text {cr }}$, was obtained from the intercept of the two linear segments of the Tafel slope from the cathodic and anodic polarization plots. ${ }^{19,20}$ The corrosion rate $\left(C_{R}\right)$ was calculated from the mathematical relationship:

$$
C_{R}=\frac{0.00327 \times J_{\mathrm{cr}} \times E_{\mathrm{qv}}}{d},
$$

where $E_{\mathrm{qv}}$ is the sample equivalent weight in grams, 0.00327 is a constant for corrosion rate calculation in $\mathrm{mm} / \mathrm{y}^{21}$ and $d$ is the density in $\mathrm{g}$. The inhibition efficiency $\left(\eta_{2}, \%\right)$ was determined from the corrosion rate values according to Eq. (2):

$$
\eta_{2}=1-\left[\frac{C_{R 2}}{C_{R 1}}\right] \times 100,
$$

where $C_{R 1}$ and $C_{R 2}$ are the corrosion rates without and with BEZT compound, respectively. 
Polarization resistance $\left(R_{p}, \Omega\right)$ was calculated from Eq. (3) below:

$$
R_{p}=2.303 \frac{B_{a} B_{c}}{B_{a}+B_{c}}\left(\frac{1}{J_{\mathrm{cr}}}\right),
$$

where $B_{a}$ is the anodic Tafel slope and $B_{c}$ is the cathodic Tafel slope, both are measured as (V versus $\mathrm{Ag} / \mathrm{AgCl} / \mathrm{dec})$.

\subsection{FTIR spectroscopy and optical microscopy characterization}

$\mathrm{BEZT} / 3 \mathrm{MH}_{2} \mathrm{SO}_{4}$ solution (before and after the corrosion test) was exposed to specific range of infrared ray beams from Bruker Alpha FTIR spectrometer at a studied wavelength range of $375-7500 \mathrm{~cm}^{-1}$ and resolution of $0.9 \mathrm{~cm}^{-1}$. The transmittance and reflectance of the infrared beams at various frequencies were decoded and transformed into an FTIR absorption plot consisting of spectral peaks. The spectral pattern was evaluated and equated according to the FTIR absorption table to identify the functional groups involved in the corrosion inhibition reaction. Images of corroded and inhibited S41000SS surface morphology from optical microscopy were analyzed after weight-loss measurement with Omax trinocular through the aid of ToupCam analytical software.

\subsection{Weight loss measurement}

Measured S41000SS steel coupons separately immersed in $200 \mathrm{~mL}$ of the dilute acid test solution for
$240 \mathrm{~h}$ at $30^{\circ} \mathrm{C}$ were weighed every $24 \mathrm{~h}$ according to ASTM G31-72(2004). The corrosion rate $\left(C_{R}\right)$ is determined as follows ${ }^{22}$ :

$$
C_{R}=\left[\frac{87.6 \omega}{D A t}\right]
$$

where $\omega$ is the mass loss in mg, $D$ is the density in $\mathrm{g} /$ $\mathrm{cm}^{3}, A$ is the total surface area of the coupon in $\mathrm{cm}^{2}$ and 87.6 is a constant for corrosion rate determination in $\mathrm{mm} / \mathrm{y} . t$ is the time in $\mathrm{h}$. Inhibition efficiency $(\eta)$ was determined from the mathematical relationship:

$$
\eta=\left[\frac{\omega_{1}-\omega_{2}}{\omega_{1}}\right] \times 100
$$

where $\omega_{1}$ and $\omega_{2}$ are the mass losses at specific BEZT concentrations. Surface coverage was determined from the following relationship ${ }^{23,24}$ :

$$
\theta=\left[1-\frac{\omega_{2}}{\omega_{1}}\right]
$$

where $\theta$ is the degree of the BEZT compound adsorbed per gram of the steel samples. $\omega_{1}$ and $\omega_{2}$ are the mass losses of each steel coupon at specific concentrations of BEZT in the acid solution.

\section{Results and Discussion}

\subsection{Potentiodynamic polarization}

Polarization results for the effect of BEZT on

\begin{tabular}{|c|c|c|c|c|c|c|c|c|c|c|}
\hline Sample & $\begin{array}{l}\text { BEZT } \\
\text { conc. } \\
(\%)\end{array}$ & $\begin{array}{l}\text { BEZT } \\
\text { conc. } \\
(\mathrm{M})\end{array}$ & $\begin{array}{c}\text { Corrosion } \\
\text { rate, } \\
C_{R} \\
(\mathrm{~mm} / \mathrm{y})\end{array}$ & $\begin{array}{c}\text { BEZT } \\
\text { inhibition } \\
\text { efficiency, } \\
\eta_{2}(\%)\end{array}$ & $\begin{array}{c}\text { Corrosion } \\
\text { current } \\
\text { (A) }\end{array}$ & $\begin{array}{c}\text { Corrosion } \\
\text { current } \\
\text { density, } \\
J_{\mathrm{cr}} \\
\left(\mathrm{A} / \mathrm{cm}^{2}\right)\end{array}$ & $\begin{array}{c}\text { Corrosion } \\
\text { potential, } \\
E_{\mathrm{cr}}(\text { versus } \\
\mathrm{Ag} / \mathrm{AgCl})\end{array}$ & $\begin{array}{c}\text { Polarization } \\
\text { resistance, } \\
\quad R_{p}(\Omega)\end{array}$ & $\begin{array}{c}\text { Cathodic } \\
\text { Tafel } \\
\text { slope, } B_{c} \\
\text { (V versus } \\
\mathrm{Ag} / \mathrm{AgCl} / \\
\text { dec) }\end{array}$ & $\begin{array}{c}\text { Anodic } \\
\text { Tafel } \\
\text { slope, } B_{a} \\
(\mathrm{~V} \text { versus } \\
\mathrm{Ag} / \mathrm{AgCl} / \\
\text { dec) }\end{array}$ \\
\hline A & 0 & 0 & 18.45 & 0 & $8.42 \mathrm{E}-04$ & $1.68 \mathrm{E}-03$ & -0.332 & 30.53 & -9.695 & 4.313 \\
\hline B & 0.13 & $9.246 \mathrm{E}-06$ & 3.07 & 83.38 & $1.40 \mathrm{E}-04$ & $2.80 \mathrm{E}-04$ & -0.254 & 584.10 & -10.540 & 12.840 \\
\hline $\mathrm{C}$ & 0.25 & $1.849 \mathrm{E}-05$ & 4.31 & 81.39 & $1.57 \mathrm{E}-04$ & $3.31 \mathrm{E}-04$ & -0.284 & 517.40 & -10.330 & 15.310 \\
\hline $\mathrm{D}$ & 0.38 & $2.774 \mathrm{E}-05$ & 3.00 & 83.71 & $1.37 \mathrm{E}-04$ & $2.74 \mathrm{E}-04$ & -0.237 & 587.80 & -9.367 & 7.914 \\
\hline $\mathrm{E}$ & 0.50 & $3.698 \mathrm{E}-05$ & 2.57 & 86.07 & $1.17 \mathrm{E}-04$ & $2.34 \mathrm{E}-04$ & -0.253 & 416.30 & -9.600 & 2.868 \\
\hline $\mathrm{F}$ & 0.63 & $4.623 \mathrm{E}-05$ & 3.17 & 82.83 & $1.45 \mathrm{E}-04$ & $2.89 \mathrm{E}-04$ & -0.238 & 477.80 & -9.411 & 3.174 \\
\hline G & 0.75 & $5.547 \mathrm{E}-05$ & 3.81 & 82.89 & $1.44 \mathrm{E}-04$ & $2.88 \mathrm{E}-04$ & -0.224 & 432.50 & -8.945 & 3.630 \\
\hline
\end{tabular}
S41000SS corrosion are shown in Table 1 and Fig. 2 depicts the polarization plots. The values in Table 3

Table 1. Polarization data for S41000SS in (0.13-0.75\%) BEZT/3 $\mathrm{MH}_{2} \mathrm{SO}_{4}$ solution. 


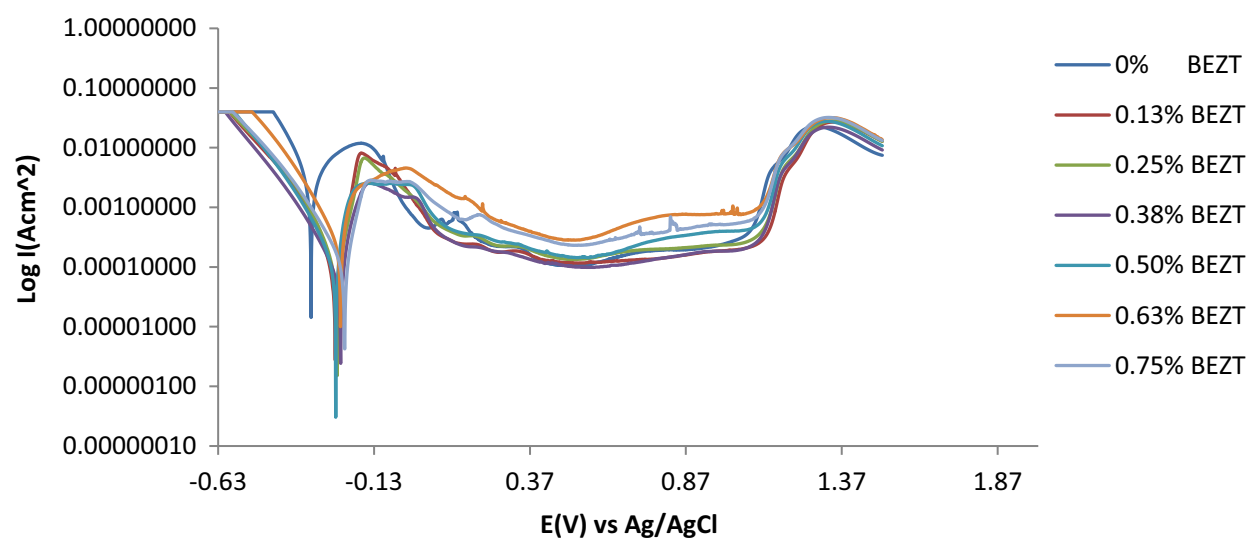

Fig. 2. (Color online) Potentiodynamic polarization plots for S41000SS in (0.13-0.75\%) BEZT/3 $\mathrm{MH}_{2} \mathrm{SO}_{4}$ solution.

show the significant variation in corrosion rates and other potentiostatic parameters between the uninhibited and BEZT-inhibited samples. BEZT performed effectively at all concentrations (very low concentrations) studied with a maximum inhibition efficiency of $86.07 \%$ at $0.5 \%$ BEZT concentration. This is due to the adsorption of BEZT molecules on the steel surface forming a protective barrier film and blocking the active sites on the metal surface. ${ }^{25,26}$ Changes in BEZT concentration had no significant influence on the corrosion rate and inhibition efficiency values. This observation aligns with the values obtained for polarization resistance (Table 1) and corrosion current densities, which generally remained similar at all BEZT concentrations. The corrosion potential of S41000SS at $0 \%$ BEZT at $-0.330 \mathrm{~V}$ versus $\mathrm{Ag} / \mathrm{AgCl}$ differs from values obtained at $0.13-$ $0.75 \%$ BEZT due to the presence of an effective BEZT film as mentioned earlier, which inhibits the electrolytic transport of corrosive sulfate anions $\left(\mathrm{SO}_{4}^{2-}\right)$ and metallic cations which may result from oxidation. ${ }^{27}$ Despite the minimal variation observed for cathodic tafel slopes, the inhibitor did alter the hydrogen evolution and oxygen reduction mechanism of the cathodic reaction process; however, values obtained for anodic Tafel slope show that BEZT had a stronger influence on the anodic dissolution mechanisms. ${ }^{28}$ The potentiodynamic polarization plots in Fig. 2 show active and anodic-passivation between the uninhibited and inhibited S41000SS samples. The polarization graph for $0 \%$ BEZT with a corrosion potential of $-0.330 \mathrm{~V}$ versus $\mathrm{Ag} / \mathrm{AgCl}$ corresponds to the active redox electrochemical mechanism, resulting in accelerated deterioration of the alloys.
At $0.13-0.75 \%$ BEZT, the corrosion potentials shift to the anodic potentials signifying anodic inhibition through electrostatic interaction between the negatively charged Fe surface and the protonated inhibitor. This process stifles the oxidation reactions responsible for S41000SS dissolution. The highest change in corrosion potential in $\mathrm{H}_{2} \mathrm{SO}_{4}$ is $108 \mathrm{mV}$ in the anodic direction, and thus BEZT is an anodic type inhibitor. ${ }^{29-31}$

\subsection{ATR-FTIR spectroscopy analysis}

Identification of the functional groups responsible for BEZT inhibition on S41000SS in $\mathrm{H}_{2} \mathrm{SO}_{4}$ solution was done through ATR-FTIR spectroscopy and matched with the ATR-FTIR table ${ }^{32,33}$ for identification. The ATR-FTIR spectra of $3 \mathrm{MH}_{2} \mathrm{SO}_{4} / \mathrm{BEZT}$ solution before and after the corrosion tests are shown in Fig. 3. The spectral diagrams show the same peak configuration for both test solutions but vary in intensity, suggesting that the dominant anodic inhibition properties of BEZT are through surface coverage and suppression of the redox electrochemical process. The spectral peaks for the test solution after corrosion decreased significantly at some wavenumbers between 3348.98 and $579.33 \mathrm{~cm}^{-1}$ due to adsorption as a result of the electrochemical reaction of specific molecules and functional groups of BEZT with S41000S surface in inhibiting the corrosion of the steel. The spectra peaks of $3348.96,1633.25$, $1175.48,1044.92,881.02$ and $579.33 \mathrm{~cm}^{-1}$ corresponds to $\mathrm{O}-\mathrm{H}$ stretch, H-bonded (alcohols and phenols), N-H stretch (primary, secondary amines, 


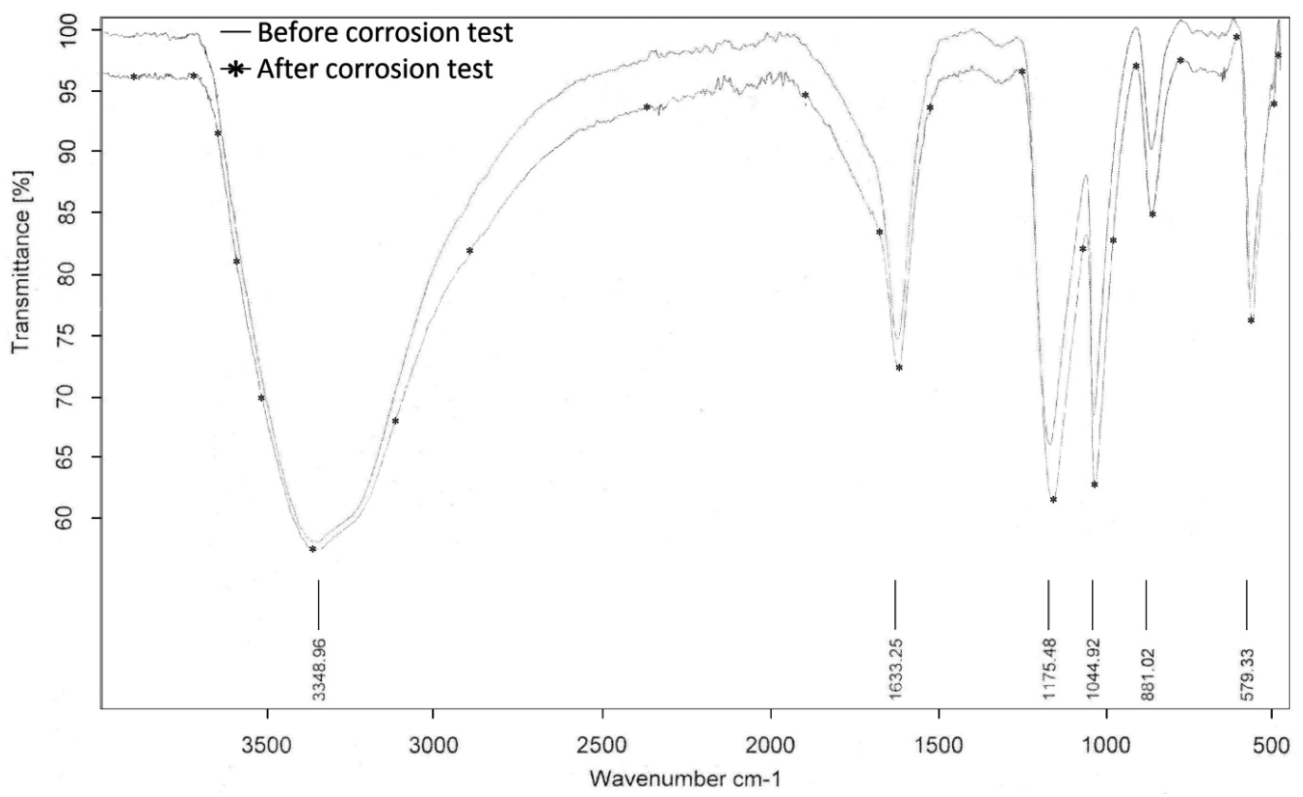

Fig. 3. ATR-FTIR spectra of BEZT compound in $3 \mathrm{MH}_{2} \mathrm{SO}_{4}$ solution before and after S41000SS corrosion.

amides) and C-H "oop" (aromatics). Past research has shown amines, alcohols and hydroxides functional groups to be effective corrosion inhibitors. ${ }^{34,35}$

BEZT being an aromatic heterocyclic compound with the chemical formula $\mathrm{C}_{7} \mathrm{H}_{5} \mathrm{NS}$ consists of a 5 -membered 1,3-thiazole ring attached to a benzene ring. Considering its structure, several points of inhibitor/metal interaction can be identified. The free electron pairs on $\mathrm{N}$ and $\mathrm{S}$ and the $\pi$-electrons from the aromatic rings are capable of forming covalent bonds with Fe substrate metal. The double bonds in the molecule enable reverse donation of metal d-electrons to the pi-orbitals. S-atoms in the BEZT molecular structure due to their lower solubility, excess free lone pair of electrons and greater polarizability enable the formation of the $\mathrm{d} \pi-\mathrm{d} \pi$ bond, resulting from the overlapping of 3 d-electrons which enhances the adsorption of the inhibitor onto the metal. The $\mathrm{N}$ atom of the amino group attached to the thiazole ring enhances the BEZT to adsorb onto the steel. ${ }^{36,37}$

\subsection{Weight loss and optical microscopy}

Data from weight loss analysis of S41000SS in $3 \mathrm{MH}_{2} \mathrm{SO}_{4}$ at $0-0.75 \%$ BEZT are shown in Table 2. Figures 4 and 5 show the plot of S41000SS corrosion rate and BEZT inhibition efficiency versus exposure time in the acid solution. The optical micrographs for the steel specimen before and after corrosion are shown in Figs. 6(a)-8(b). Observation of Fig. 4 shows the significant contrast between the uninhibited and inhibited stainless steel during the exposure hours. The corrosion rate of the uninhibited steel remained generally high. At $24 \mathrm{~h}$, the corrosion rate

Table 2. Weight loss results measurement for S41000SS in (0.13-0.75\%) BEZT/3 $\mathrm{MH}_{2} \mathrm{SO}_{4}$ solution.

\begin{tabular}{lccccc}
\hline Samples & $\begin{array}{c}\text { BEZT } \\
\text { concentration }(\%)\end{array}$ & $\begin{array}{c}\text { BEZT } \\
\text { concentration }(\mathrm{M})\end{array}$ & $\begin{array}{c}\text { Weight } \\
\text { loss }(\mathrm{g})\end{array}$ & $\begin{array}{c}\text { Corrosion rate } \\
(\mathrm{mm} / \mathrm{y})\end{array}$ & $\begin{array}{c}\text { BEZT inhibition } \\
\text { efficiency }\end{array}$ \\
\hline $\mathrm{A}$ & 0 & 0 & 2.449 & 0.0575 & 0 \\
$\mathrm{~B}$ & 0.13 & $9.25 \mathrm{E}-06$ & 0.039 & 0.0009 & 98.40 \\
$\mathrm{C}$ & 0.25 & $1.85 \mathrm{E}-05$ & 0.032 & 0.0008 & 98.68 \\
$\mathrm{D}$ & 0.38 & $2.77 \mathrm{E}-05$ & 0.045 & 0.0011 & 98.17 \\
$\mathrm{E}$ & 0.50 & $3.70 \mathrm{E}-05$ & 0.027 & 0.0006 & 98.91 \\
$\mathrm{~F}$ & 0.63 & $4.62 \mathrm{E}-05$ & 0.031 & 0.0007 & 98.75 \\
$\mathrm{G}$ & 0.75 & $5.55 \mathrm{E}-05$ & 0.027 & 0.0006 & 98.90 \\
\hline
\end{tabular}




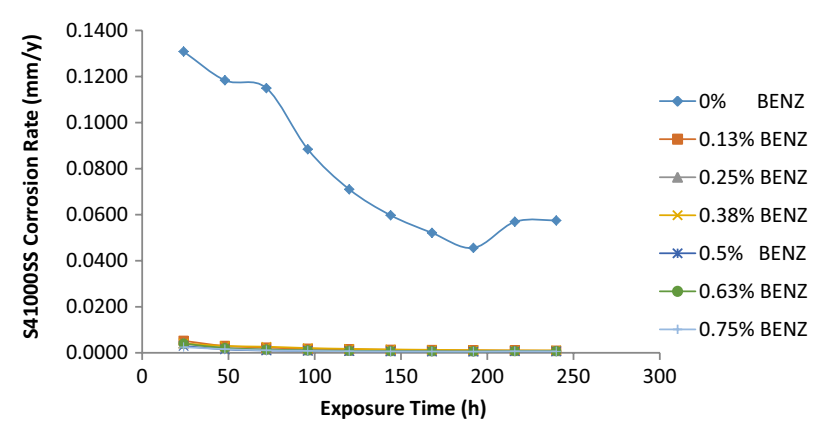

Fig. 4. (Color online) Plot of S41000SS corrosion rates $(\mathrm{mm} / \mathrm{y})$ versus exposure time $(\mathrm{h})$.

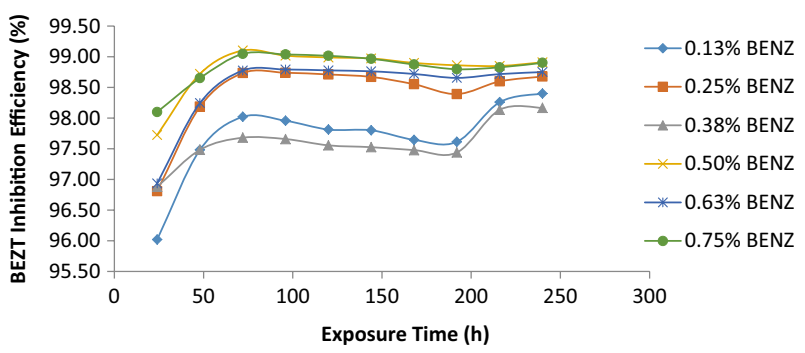

Fig. 5. (Color online) Plot of S41000SS inhibition efficiencies (\%) versus exposure time (h).

was $0.0131 \mathrm{~mm} / \mathrm{y}$; this value decreased progressively with time to about $0.0575 \mathrm{~mm} / \mathrm{y}$ at $240 \mathrm{~h}$. The micrograph on Figs. 7(a) and 7(b) confirms the corrosion rate values for the uninhibited steel specimen in comparison to the control steel specimen (Figs. 6(a) and $6(\mathrm{~b}))$. The image shows a badly corroded morphology full of oxides and macro-pits as a result of the debilitating action of $\mathrm{SO}_{4}^{2-}$ ions in the acid solution,

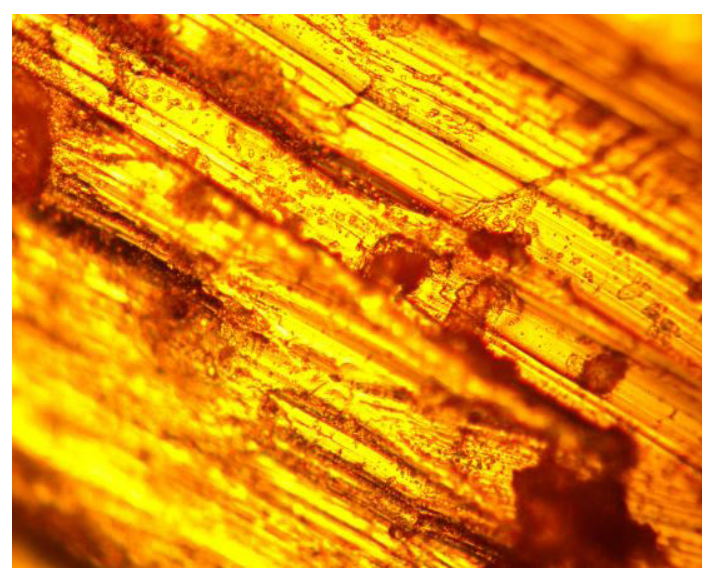

(a) which reacts with the steel surface. Observing the corrosion rate values for the inhibited steel specimens at specific BEZT concentrations (Fig. 4), similar electrochemical behavior can be deduced from the plot from 24 to $240 \mathrm{~h}$. Their corrosion rates remained generally the same throughout the exposure period at significantly low values. The electrochemical behavior of the inhibited steel specimens in interaction with the BEZT compound is clearly depicted in Fig. 5. At all BEZT concentrations, the inhibition efficiency increased progressively with time till about $72 \mathrm{~h}$, showing that the inhibiting action of BEZT is time-dependent, although at high efficiency values. Between 72 and $192 \mathrm{~h}$, their inhibition efficiencies were generally constant before increasing progressively again to the end of the exposure period. The micrographs of the inhibited steel specimens confirm their corrosion behavior on the weight loss plot, as the surface morphology shows a slightly corroded or etched surface due to the competitive action of corrosive ions and the protonated inhibitor molecule before the inhibitor completely adsorbed onto the steel and inhibited further action of the corrosive species.

\subsection{Adsorption isotherm}

Electrostatic adsorption of the BEZT compound onto the alloy surface inhibits the corrosion process. Adsorption isotherm gives useful information on the quantitative adsorption of BEZT molecules for a given set of state variables. The amount of the adsorbed material is known as surface coverage $\theta$. The Langmuir

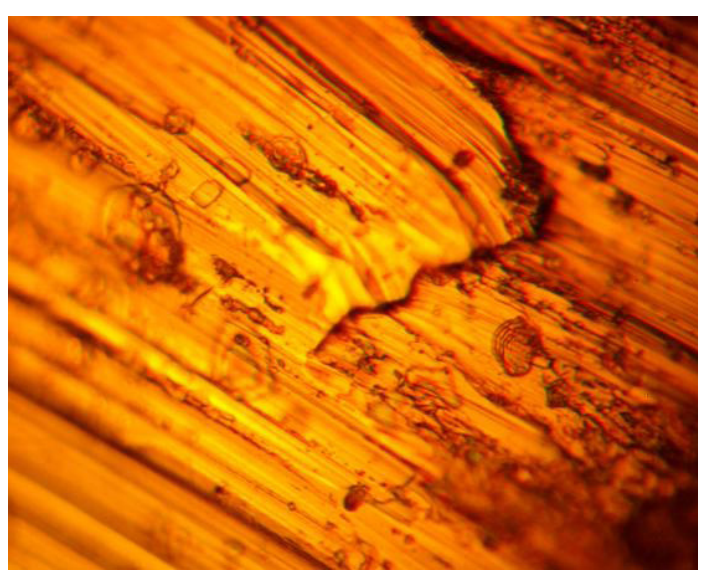

(b)

Fig. 6. (Color online) Optical microscopy image of S41000SS control specimen: (a) mag. $\times 40$ and (b) mag. $\times 100$. 


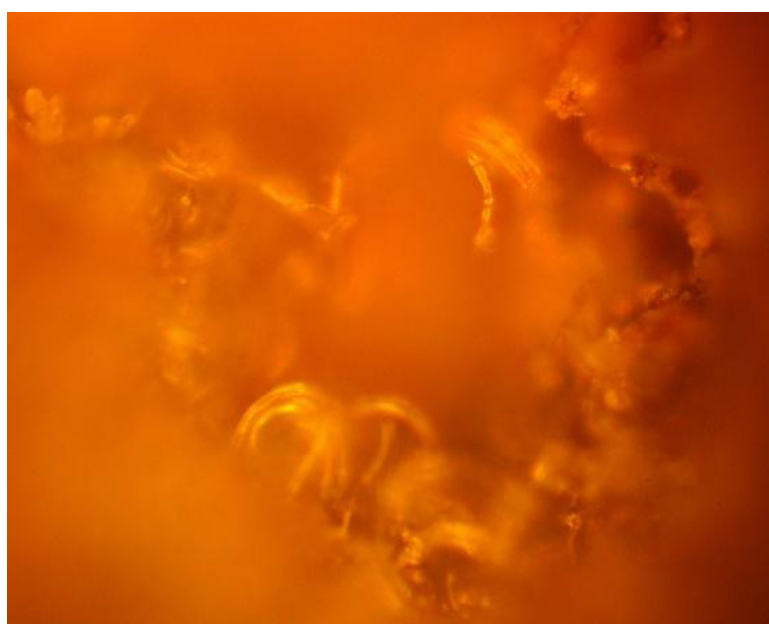

(a)

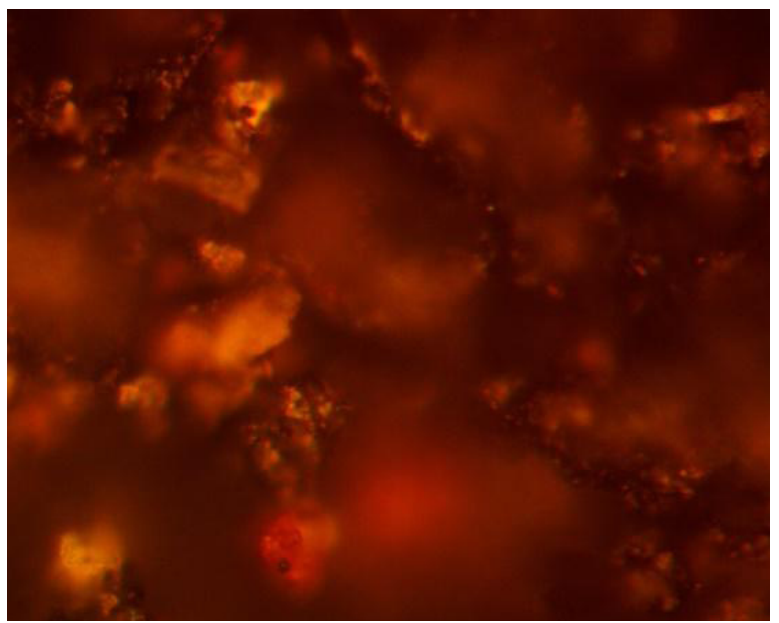

(b)

Fig. 7. (Color online) Optical microscopy image of S41000SS corroded specimen: (a) mag. $\times 40$ and (b) mag. $\times 100$.

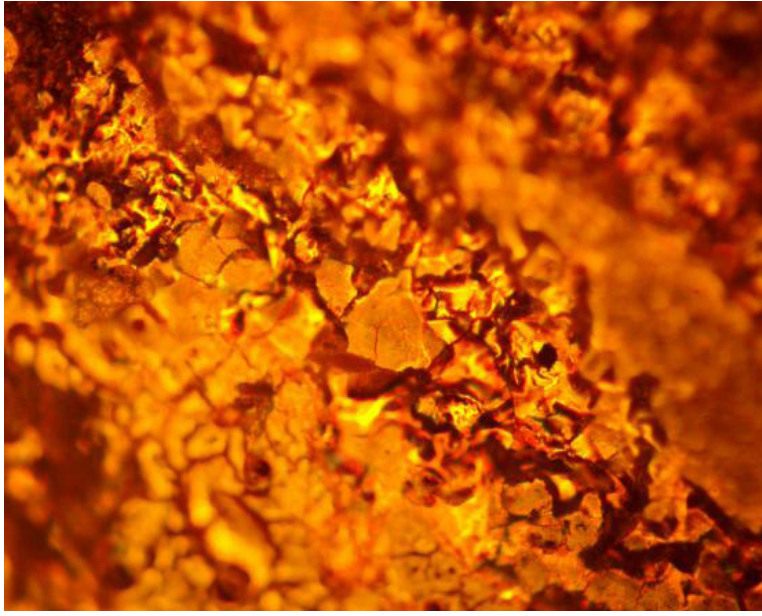

(a)

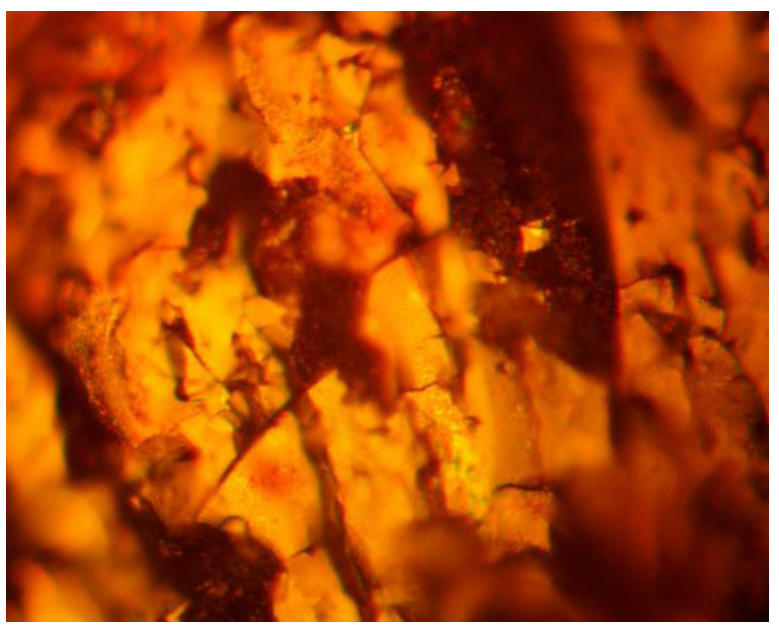

(b)

Fig. 8. (Color online) Optical microscopy image of S41000SS inhibited specimen: (a) mag. $\times 40$ and (b) mag. $\times 100$.

adsorption isotherm model among other isotherms produced best fitting for the results obtained for BEZT on $\mathrm{S} 41000 \mathrm{SS}$ in $3 \mathrm{MH}_{2} \mathrm{SO}_{4}$ acid solutions.

The Langmuir isotherm is conventionally expressed $\operatorname{as}^{38,39}$ :

$$
\theta=\left[\frac{K_{\mathrm{ads}} C}{1+K_{\mathrm{ads}} C}\right]
$$

where $\theta$ is the degree of surface coverage of the inhibitor on the alloy surface, $C$ is the BEZT concentration in $\mathrm{H}_{2} \mathrm{SO}_{4}$ acid media and $K_{\text {ads }}$ is the equilibrium

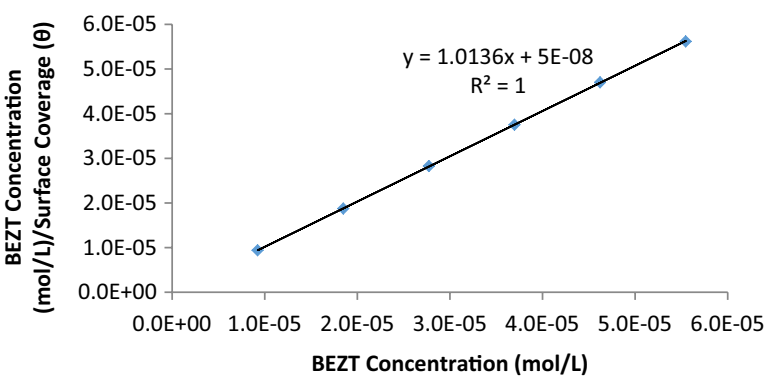

Fig. 9. (Color online) Plot of $\frac{C}{\theta}$ versus BEZT concentration $(C)$ in $3 \mathrm{MH}_{2} \mathrm{SO}_{4}$. 
Table 3. Results for standard free energy, surface coverage and equilibrium constant of adsorption for $0.13-0.75 \% \mathrm{BEZT} / 3 \mathrm{MH}_{2} \mathrm{SO}_{4}$.

\begin{tabular}{lcccc}
\hline Samples & $\begin{array}{c}\text { BEZT } \\
\text { concentration }(\mathrm{M})\end{array}$ & $\begin{array}{c}\text { Surface } \\
\text { coverage }(\theta)\end{array}$ & $\begin{array}{c}\text { Equilibrium constant } \\
\text { of adsorption }(K)\end{array}$ & $\begin{array}{c}\text { Standard free energy } \\
\text { of adsorption, } \Delta G_{\text {ads }}^{\text {o }}(\mathrm{kJ} / \mathrm{mol})\end{array}$ \\
\hline B & $9.25 \mathrm{E}-06$ & 0.9840 & $6.65 \mathrm{E}+06$ & -48.88 \\
$\mathrm{C}$ & $1.85 \mathrm{E}-05$ & 0.9868 & $4.03 \mathrm{E}+06$ & -47.64 \\
$\mathrm{D}$ & $2.77 \mathrm{E}-05$ & 0.9817 & $1.93 \mathrm{E}+06$ & -45.82 \\
$\mathrm{E}$ & $3.7 \mathrm{E}-05$ & 0.9891 & $2.45 \mathrm{E}+06$ & -46.41 \\
$\mathrm{~F}$ & $4.62 \mathrm{E}-05$ & 0.9875 & $1.71 \mathrm{E}+06$ & -45.52 \\
$\mathrm{G}$ & $5.55 \mathrm{E}-05$ & 0.9890 & $1.62 \mathrm{E}+06$ & -45.39 \\
\hline
\end{tabular}

constant of the adsorption process. The plots of $\frac{C}{\theta}$ versus the BEZT concentration were linear (Fig. 9), confirming the Langmuir adsorption.

Based on the assumptions of Langmuir isotherm, all adsorption sites are equivalent and have the same binding energy to the surface. BEZT-protonated molecules adsorb over the entire surface at the metal/ solution boundary without causing any change in the slope from unity (Fig. 9). ${ }^{40}$ Increase in BEZT concentration caused changes in its energy of adsorption in comparison with water molecules as BEZT molecules became more concentrated on the steel.

\subsection{Thermodynamics of the corrosion inhibition mechanism}

The equilibrium constant of adsorption $K_{\text {ads }}$ is related to the standard free energy of adsorption, $\Delta$ $G_{\text {ads }}$ by the expression in Eq. (8). Data obtained for $\Delta G_{\text {ads }}^{\mathrm{o}}$ as a result of BEZT adsorption on S41000SS (Table 3) were calculated from the following relationship:

$$
\Delta G_{\mathrm{ads}}=-2.303 R T \log \left[55.5 K_{\mathrm{ads}}\right],
$$

where 55.5 is the molar concentration of water in the solution, $R$ is the universal gas constant, $T$ is the absolute temperature and $K_{\text {ads }}$ is the equilibrium constant of adsorption for BEZT. The negative values of $\Delta G_{\text {ads }}$ show that the adsorbed layer on the S410SS surface is stable and the adsorption process is spontaneous. ${ }^{41}$ The calculated values ranged between $-45.39<\Delta G_{\text {ads }}<-48.88 \mathrm{~kJ} / \mathrm{mol}$, which is higher than the threshold value $(-40 \mathrm{~kJ} / \mathrm{mol})$ necessary for chemisorption adsorption resulting from charge sharing or a transfer from the BEZT cations to the charged metal surface. ${ }^{42}$ The varied properties of the S41000SS surface are responsible for the differences in
$\Delta G_{\mathrm{ads}}^{\mathrm{o}}$ for BEZT inhibitor in direct proportion to changes in surface coverage values as shown in Table $3 .^{43,44}$

\section{Conclusion}

BEZT effectively inhibited the corrosion of the martensitic stainless steel in the acid media through electrostatic attraction and covalent bonding, resulting from chemisorption mechanism onto the steel surface. The inhibition efficiency values remained sufficiently high from the onset of the exposure hours till the end due to the inhibition reaction of the molecular functional groups and heteroatoms of the compounds, which strongly altered the mechanism of the electrochemical process, protecting the steel from corrosion. The inhibition property of the compound was determined to be anodic-type inhibitor.

\section{Acknowledgment}

The author acknowledges Covenant University Ota, Ogun State, Nigeria for sponsorship and provision of facilities for the research project.

\section{References}

1. World of chemicals. http://www.worldofchemicals. com/430/chemistry-articles/industrial-applicationsof-sulfuric-acid.html (retrieved 31 March 2017).

2. E. H. Phelps and D. C. Vreeland, Corrosion 13 (1957) 21.

3. M. Abdallah, Mater. Chem. Phys. 82 (2003) 786.

4. A. Groysman, Corrosion Control Measures, Corrosion for Everybody (Springer, The Netherlands, 2010), pp. $151-188$.

5. A. M. Alsabagh, M. A. Migahed and H. S. Awad, Corros. Sci. 48 (2006) 813. 
6. R. A. Prabhu, T. V. Venkatesha, A. V. Shanbhag, G. M. Kulkarni and R. G. Kalkhambkar, Corros. Sci. 50 (2008) 3356.

7. M. Finsgar and D. K. Merl, Corros. Sci. 83 (2014) 164.

8. A. Doner, R. Solmaz, M. Özcan and G. Kardas, Corros. Sci. 53 (2011) 2902.

9. H. M. Abd El-Lateef, M. A. Abo-Riya and A. H. Tantawy, Corros. Sci. 108 (2016) 94.

10. G. Moretti, F. Guidi and F. Fabris, Corros. Sci. 76 (2013) 206.

11. A. Kloepfer, M. Jekel and T. Reemtsma, J. Chromatogr. A 1058 (2004) 81.

12. M. Ajmal, A. S. Mideen and M. A. Khan, Corros. Sci. 36 (1994) 79.

13. B. V. Appa Rao, Md. Yakub Iqbal and B. Sreedhar, Corros. Sci. 51 (2009) 1441.

14. A. M. Al-Mayouf, A. A. Al-Suhybani and A. K. AlAmeery, Desalination 16 (1998) 25.

15. Stainless Steel-Grade 410 (UNS S41000). http://www. azom.com/article.aspx?ArticleID=970 (retrieved 31 March 2017).

16. ASTM G1-03 (2011), Standard practice for preparing, cleaning, and evaluating corrosion test specimens. http://www.astm.org/Standards/G1 (retrieved 30 May 2016).

17. ASTM G59-97 (2014), Standard test method for conducting potentiodynamic polarization resistance measurements. http://www.astm.org/Standards/G31 (retrieved 30 May 2016).

18. ASTM G102-89 (2015)e1, Standard practice for calculation of corrosion rates and related information from electrochemical measurements. http://www. astm.org/Standards/G31 (retrieved 30 May 2016).

19. Basic of corrosion measurements. http://www.che.sc. edu/faculty/popov/drbnp/ECHE789b/Corrosion\% 20Measurements.pdf (retrieved 06 April 2017).

20. Measurements of corrosion rates. http://www. ecochemie.nl/download/Application notes/Autolab Application_Note_COR02.pdf (retrieved 06 April 2017).

21. Y. Choi, S. Nesic and S. Ling, Electrochim. Acta 56 (2011) 1752.

22. P. Venkatesan, B. Anand and P. Matheswaran, Eur. J. Chem. 6 (2009) S438.

23. H. U. Schutt and R. J. Horvath, Crude Column Overhead Corrosion Problem Caused by Oxidized Sulfur Species (NACE, Houston, Texas, 1987).
24. M. J. Schofield, Plant Engineer's Reference Book (Elsevier, The Netherlands, 2003).

25. R. Solmaz, E. Altunbas and G. Kardas, Mater. Chem. Phys. 125 (2011) 796.

26. A. O. Yuce and G. Kardas, Corros. Sci. 58 (2012) 86.

27. K. H. Husain and R. Jarman, Desalination 99 (1994) 113.

28. H. Zhiyong, M. Yanbin, M. Xuemei, Z. Hailin, L. Jun, L. Chao and C. Duanlin, Corros. Sci. 112 (2016) 563.

29. M. Finšgar and J. Jackson, Corros. Sci. 86 (2014) 17.

30. L. Dieter, Corrosion and Surface Chemistry of Metals (EPFL Press, Lausanne, Switzerland, 2007), p. 67.

31. J. Y. N. Philip, J. Buchweshaija and A. Mwakalesi, Mater. Sci. Appl. 7 (2016) 396.

32. Table of Characteristic IR Absorptions. http://orgchem.colorado.edu/Spectroscopy/ specttutor/irchart. pdf (retrieved 12 January 2017).

33. S. George, Infrared and Raman Characteristic Group Frequencies: Tables and Charts (John Wiley \& Sons, New York, 2004).

34. O. Benali, H. Benmehdi, O. Hasnaoui, C. Selles and R. Salghi, J. Mater. Environ. Sci. 4 (2013) 127.

35. A. S. Fouda, H. A. Mostafa, F. El-Taib and G. Y. Elewady, Corros. Sci. 47 (2005) 1988.

36. N. K. Patel, S. C. Makwana and M. M. Patel, Corros. Sci. 14 (2004) 91.

37. J. Hojat, A. Kazem and D. Iman, Arab. J. Chem. (2014). http://dx.doi.org/10.1016/j.arabjc.2014.11.018 (retrieved 06 April 2017).

38. S. S. El-Egamy, Corros. Sci. 50 (2008) 928.

39. A. H. H. Dorian, G. Maliheh, C. Wojciech and G. Yixiang, Langmuir 30 (2014) 15143.

40. R. T. Loto and C. A. Loto, Cogent Chem. 2 (2016), https://doi.org/10.1080/23312009.2016.1268377.

41. J. Flis and T. Zakroczymski, J. Electrochem. Soc. 143 (1996) 2458.

42. F. Bentiss, M. Lebrini and M. Lagrene, Corros. Sci. 47 (2005) 2915.

43. B. B. Damaskin and A. N. Frumkin, Adsorption of Molecules on Electrodes (Wiley-Interscience, London, 1971), p. 36.

44. X. H. Li, S. D. Deng, H. Fu and G. N. Mu, J. Appl. Electrochem. 39 (2009) 1125. 